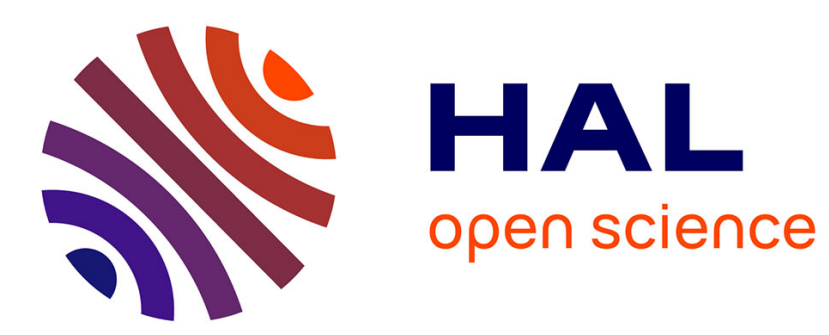

\title{
Influence of age of chicks on maternal behaviour in domestic hens
}

\author{
Marie-Annick Richard-Yris, Gérard Leboucher
}

\section{To cite this version:}

Marie-Annick Richard-Yris, Gérard Leboucher. Influence of age of chicks on maternal behaviour in domestic hens. Bird Behavior, 1987, 7 (2), pp.82-86. 10.3727/015613887791918042 . hal-01327753

\section{HAL Id: hal-01327753 \\ https://hal-univ-rennes1.archives-ouvertes.fr/hal-01327753}

Submitted on 5 Sep 2019

HAL is a multi-disciplinary open access archive for the deposit and dissemination of scientific research documents, whether they are published or not. The documents may come from teaching and research institutions in France or abroad, or from public or private research centers.
L'archive ouverte pluridisciplinaire HAL, est destinée au dépôt et à la diffusion de documents scientifiques de niveau recherche, publiés ou non, émanant des établissements d'enseignement et de recherche français ou étrangers, des laboratoires publics ou privés. 


\title{
Influence of Age of Chicks on Maternal Behaviour in Domestic Hens
}

\author{
M.A. Richard-Yris and G. Leboucher \\ Laboratoire d'Ethologie, UA CNRS 373, \\ Avenue du Général Leclerc, 35042 Rennes Cédex, France
}

\begin{abstract}
RICHARD-YRIS, M.A. and G. LEBOUCHER. 1987. Influcnce of age of chicks on maternal behaviour in domestic hens. Bird Behaviour 7: 82-86.

Newly hatched and eight day-old chicks induced maternal responses in hens without previous maternal experience. However, maternal behaviour emerged sooner in hens confined with younger chicks. Replacement of eight or 15 day-old chicks by newly-hatched ones, clearly indicated that all hens, whatever their prior experience, were capable of immediately expressing appropriate maternal responses, including high brooding amount. Brooding stances were mainly exhibited towards very young chicks (i.e. one or two days old).
\end{abstract}

Hen

Maternal behaviour

Newly-hatched chicks

Older chicks

\section{Introduction}

In natural broods of Gallinaceous birds, relationships between chicks and hens change qualitatively and quantitatively with age of chicks. In particular, physical contact between mother and young decreases gradually $(1,9)$. We found similar changes after maternal responses had been induced by forced confinement (sensitization) of hens Gallus gallus domesticus with chicks (7). Whereas the majority of authors used newly-hatched or very young chicks to induce maternal behaviour (e.g. 2,3) some have used older ones (8). However, the possible influence of chick age on rate of emergence of maternal-filial bounding and on the dynamics of hen-chick interactions has not been considered.

\section{Methods}

Subjects. The subjects were one year old Vedette, JV15 hens (a heavy dwarf strain) obtained from an industrial breeding centre. Each hen was placed individually in a wire-mesh cage $(100 \times 70 \times 60 \mathrm{~cm})$ with opaque lateral partitions and provided with a wooden nest-box $(40 \times 30 \times 40 \mathrm{~cm})$. Each animal was isolated visually but not auditorily from the others. Temperature in the experimental room was $20 \pm 2^{\circ} \mathrm{C}$. Animals were under a constant artificial photoperiod (8L: 16D).

Procedure. To ensure rapid assumption of maternal responses egg-laying was stopped artificially (5). The animals were submitted to a food deprivation period similar to that used by Wilson, Nesbeth, Douglas and Miller (11): food was withheld for seven days and water withheld concurrently during the first three days; afterwards, the subjects were fed with unrestricted amounts of corn. After the beginning of the dark cycle on the fourth day of refeeding (designated day 0 for the behavioural protocol), hens were shut in their nesting boxes where they usually spent the night. Two hours later, two chicks were carefully placed with each hen. The following morning, the nesting box door was removed 30 minutes before the lights came on, allowing the animals free access to the whole cage. A group of 10 hens (called the young group) received newlyhatched chicks (mean weight: $47.5 \pm 0.8 \mathrm{~g}$ ) and a second group of 10 hens (called the old group) received eight day old chicks with wing feathers already emerging (mean weight: $111.1 \pm 5.0 \mathrm{~g}$ ). Chicks were systematically replaced beneath hens overnight up to day 3 , to ensure nocturnal brooding. The chicks remained with foster hens until day 8 and were then replaced overnight by 2 newly-hatched chicks.

Observations and auditory tests. All hens were observed on days $1,2,3,4,8$ and 9 , over one 5 hour period, during which observations of individuals were made every ten minutes. During each sampling, the distance between hen and chicks and aggressive behaviours (pecks) were recorded. In the results, the 


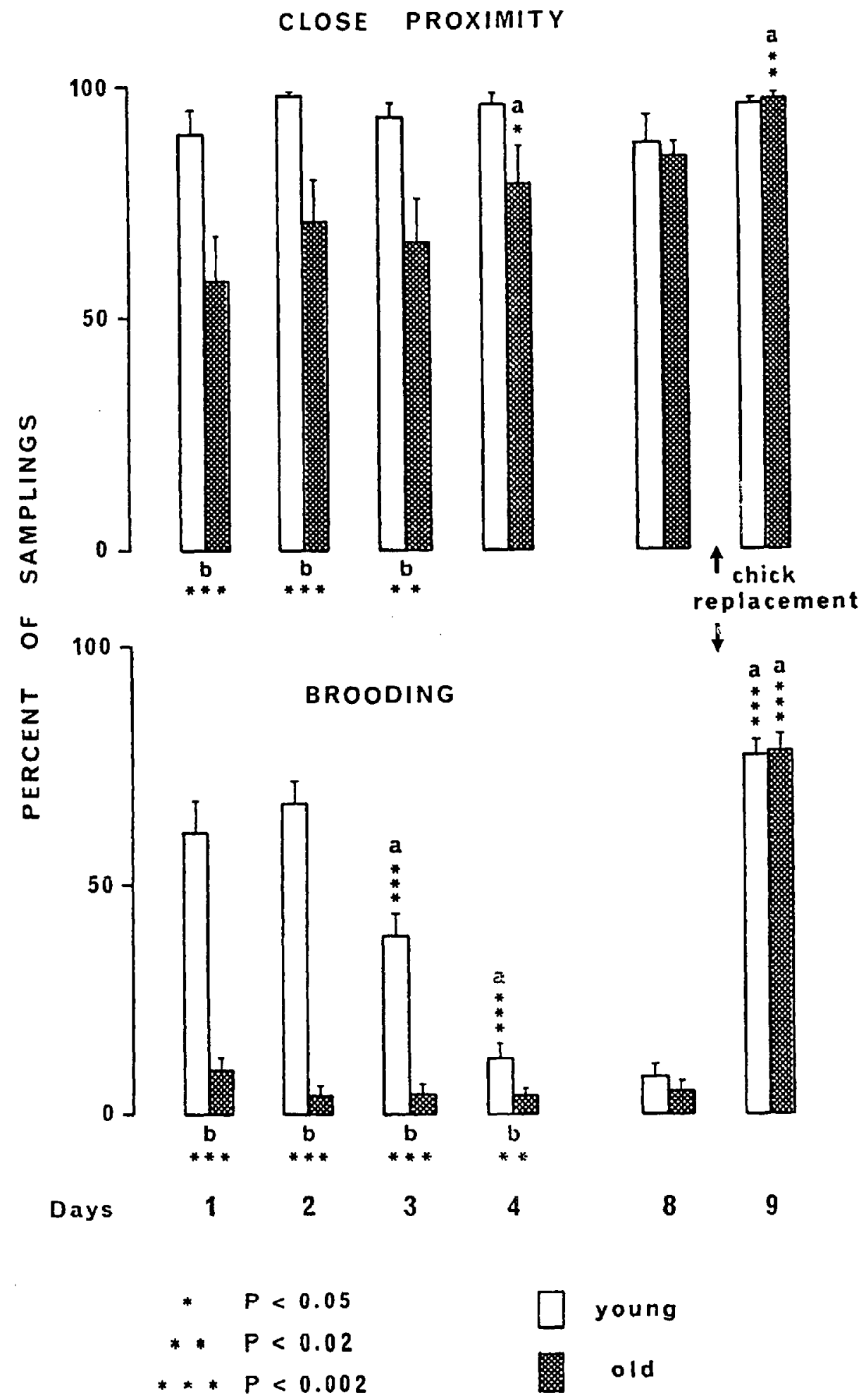

Figure 1. Responses of hens to young and old chicks and after chick replacement. a. significant difference between consecutive days (Wilcoxon matched pairs test; two-tailed). b. significant difference between groups (Mann-Whitney U test; two-tailed). 
amount of close proximity is presented as a percentage of samplings in which the distance between the hen and at least one of the two chicks, was less than $10 \mathrm{~cm}$. The amount of brooding is presented as a percentage of samplings in which at least one of the two chicks was being brooded by the hen.

On days $2,3,4,8$ and 9 , hens were temporarily separated from their chicks after completion of daily observations and subjected to auditory tests involving exposure to two minutes to a standard recording of chick distress calls. Hen clucks in response to the distress calls were counted.

\section{Results}

In general, hens showed little aggressiveness towards chicks. Two hens in the young group pecked chicks during the first three days of exposure and two hens in the old group behaved similarly. For hens in the young group, the close proximity score was stable (time trend from day 1 to 8; Friedman two-way analysis of variance: $\mathrm{X}^{2} \mathrm{r}=6.8$; NS) and always above $80 \%$ (Figure 1 ). Brooding intensity was high (i.e. greater than $60 \%$ ) for the first two days, but decreased subsequently (time trend from day 1 to 8; Friedman two-way analysis of variance: $\left.\mathrm{X}^{2} \mathrm{r}=31.5 ; \mathrm{P}<0.01\right)$. Replacement of chicks resulted in a sharp rise on day 9 (vs. day 8). Close proximity scores for hens in the old group were about $50 \%$ on day 1 and increased gradually to $80 \%$ on day 8 (time trend from day 1 to 8; Friedman two-way analysis of variance: $\mathrm{X}^{2} \mathrm{r}=11.1 ; \mathrm{P}<0.05$ ); they increased still further after chick replacement. Brooding was consistently low (i.e. less than $10 \%$ ) for these hens and only increased after chick replacement. Close proximity and brooding scores were consistently higher for broods with younger chicks over the first days of observation, but there was no difference by days 8 and 9 .

Number of clucks (Figure 2) tended to increase with time in both groups (time trend from day 1 to 8; Friedman two-way analysis of variance $\mathrm{X}^{2} \mathrm{r}=14.6 ; \mathrm{P}<0.01$ for the young group and $\mathrm{X}^{2} \mathrm{r}=13.9 ; \mathrm{P}<0.01$ for the old group). However, clucks emerged more rapidly in hens maintained with young chicks (mean latency as expressed in number of tests: $1.7 \pm 0.3$ ) than in hens maintained with old ones (latency: $3.1 . \pm 0.4$ ) (MannWhitney two-tailed test; $U=19.5 ; P<0.05$ ). Consequently, on days 3 and 4 hens of the young group emitted more clucks than those of the other group. On day 8 no differences could be found between groups; on day 9 chick replacement did not provoke any significant change.

\section{Discussion}

During the experiments, aggressiveness of hens towards chicks decreased in both groups, and the number of maternal calls increased. These results are consistent with previous data showing that maternal responses emerged gradually during sensitization experiments in hens (e.g. 4,5). However, there was an appreciable lag in close proximity and maternal calling for hens maintained with older chicks over the first three days compared with hens maintained with younger ones. Young chicks appear to be more effective in promoting rapid onset of maternal behaviour. Similar trends have been found in rats: Stern and Mackinnon (10) showed that pups less than 3 days old induced matemal responsiveness more rapidly than older pups. The discrepancy observed between the two groups of hens may have originated from differences in appearance (e.g. size, fluffiness, voice), following behaviour or quality and quantity of tactile stimulations between the two groups of chicks. While there were prolonged contacts between hens and chicks in both groups overnight, daily brooding was only maintained to any extent by hens of the young group during the first three days. It is obvious from previous data that in natural broods the quantity of daily brooding is mainly determined by the chicks' thermoregulation requirements (9). The crucial role of ventral tactile contact of the hen with her young in relation to appearance and maintenance of hen maternal behaviour has been previously emphasized $(3,6)$. The increase in close proximity with time in hens of the old group was probably related to the improvement of maternal responsiveness.

Replacement of 8 or 15 day-old chicks by newlyhatched chicks clearly indicated that all hens, whatever their prior experience, were capable of expressing appropriate maternal behaviour immediately, including frequent and prolonged brooding. Brooding, often taken as an index of maternal behaviour (4), thus appears to be largely determined by chick requirements, appearance or behaviour. Brooding is not, per se, an absolute criterion of hen maternal capacity but rather represents, at a given moment, the result of complex interactions between hen and chicks. 
NUMBER OF

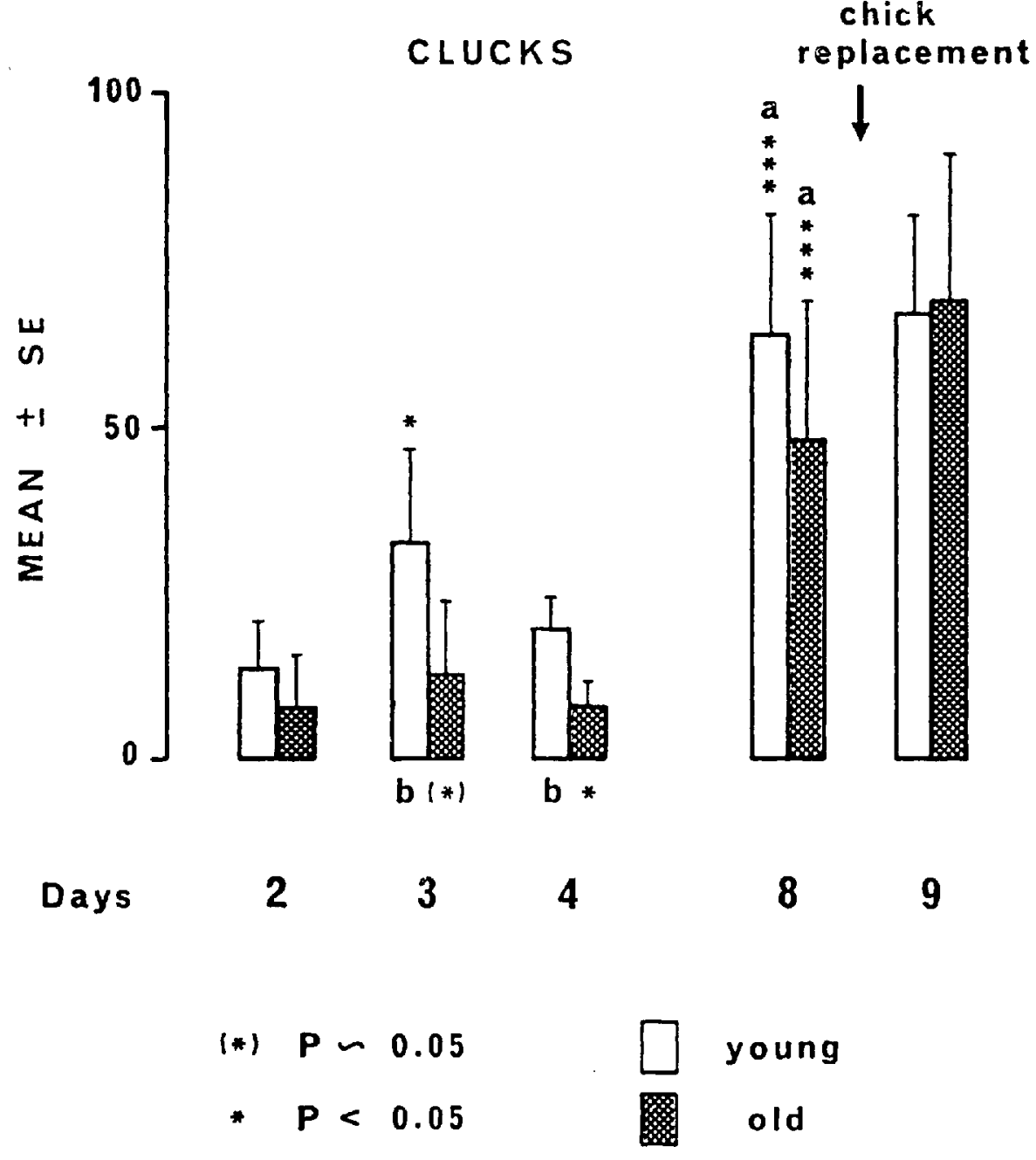

Figure 2. Number of clucks by hens. a. significant difference between consecutive days (Wilcoxon matched pairs test; two-tailed). b. significant difference between groups (Mann-Whitney U test; two-tailed).

\section{References}

1. Bateson, P.P.G. 1973. The imprinting of birds. In: Ethology and Development. Edited by S.A. Bamett. London Heineman Medical Books Ltd.

2. Burrows W.H. and T.C. Byerly. 1938. The effect of certain groups of environmental factors upon the expression of broodiness. Poultry Science 17: 324-330.

3. Maier, R.A. 1963. Maternal behavior in the domestic hen: the role of physical contact. Journal of Comparative and Physiological Psychology 56: 357-361.

4. Ramsay, A.O. 1953. Variation in the development of broodiness in fowl. Behaviour 5: 51-57.
5. Richard-Yris, M.A., D.H. Garnier and G. Leboucher. 1983. Induction of maternal behavior and some hormonal and physiological correlates in domestic hen. Hormones and Behavior 17: 345-355.

6. Richard-Yris, M.A. and G. Leboucher. 1986. Comportement maternel induit chez la poule domestique: Influence d'une séparation partielle ou totale sur le maintien de la réactivité maternelle. Comptes rendus de l'Académie des Sciences Paris Série III 302: 387-390.

7. Richard-Yris, M.A. and G. Leboucher. 1986. Comportement matemel induit chez la poule domestique: Influence du développement du poussin sur la qualité des réponses maternelles. Biology of Behaviour 11: 157-166. 
8. Sherry, D.F. 1977. Parental food-calling and the role of the young in the Burmese junglefowl (Gallus gallus spadiceus). Animal Behaviour 25: 594-601.

9. Sherry, D.F. 1981. Parental care and the development of thermoregulation in red junglefowl. Behaviour 76: 250279.

(Accepted: 1 June 1987)
10. Stern, J.M. and D.A. Mackinnon. 1978. Sensory regulation of maternal behaviour in rats: Effects of pup age. Developmental Psychobiology 11: 579-586.

11. Wilson, H.R., W.G. Nesbeth, C.R. Douglas and E.R. Miller. 1979. Forced resting bobwhite quail breeders and their subsequent reproductive performance. Poultry Science 58: 731-737. 